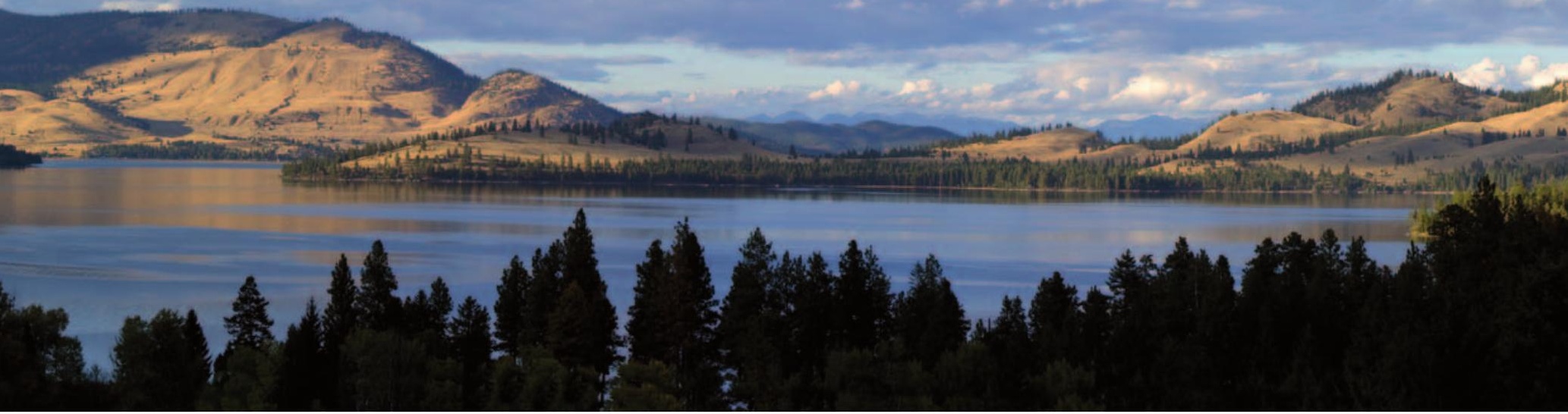

\section{Research on the reservation}

\begin{abstract}
American Indians have had some unhappy interactions with scientists in the past. Now, America's tribal colleges are rapidly expanding their own research.
\end{abstract}

\section{By Zoë Corbyn}

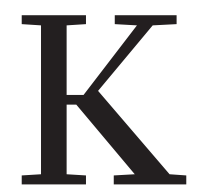

atie McDonald had never given much thought to the trout in Flathead Lake except when fishing with her family. She didn't wonder about heavy-metal pollution or how that might affect people eating the fish. But that was before the then-19year-old student started a bachelor's degree in environmental science at Salish Kootenai College in northwest Montana and had to choose a research project. She saw that trout consumption was going up on the Flathead Indian Reservation, where she lived. Poor people, in particular, had begun to receive donated fish. So McDonald set out to see whether there was cause for concern.

Her institution is a tribal college, one of 36 scattered around the United States (see 'US tribal colleges') and serving some of the leastdeveloped communities in the country. But thanks to several federal programmes seeking to boost science within tribal colleges, McDonald had access to equipment such as samples of the lake trout (Salvelinus namaycush) and found surprisingly high levels of the toxic metal ${ }^{1}$.

The results were compelling enough for the tribal government to advise women of childbearing age to avoid eating older, larger fish from the lake altogether - a more stringent recommendation than state guidelines that suggest eating no more than one a month, says Barry Hansen, the tribes' fisheries biologist.

Douglas Stevens, head of life sciences at Salish Kootenai, says that McDonald's work shows students how their scientific research can serve the local community.

That message is big change for American Indians, who have typically been research subjects rather than investigators in studies ranging from anthropology to genetics. And like indigenous peoples around the world, American Indians have sometimes been treated poorly by the scientific establishment. In a high-profile case last year, Arizona's a state-of-the-art mercury analyser. She ran
Native American researchers found raised levels of mercury in fish from Flathead Lake, Montana, which borders the Flathead Indian Researvation.

Havasupai Indian tribe settled a lawsuit it had filed against Arizona State University in Tempe for conducting genetic analyses that the tribe says were done without express permission.

That case and others have fostered a climate of suspicion among some American Indians towards mainstream researchers. But tribal colleges are now trying to harness science for their communities' own purposes by building up their capacity for both training and research. With an influx of funding from several federal agencies over the past decade, these institutions have started to hire more faculty members with research credentials, develop better facilities and establish science degree programmes.

Although there are difficulties, particularly in research quality and publication rates, supporters say that the increasing focus on scientific research at tribal colleges is helping both students and their communities.

It can be seen "as an act of resistance" says Luana Ross, the president of Salish Kootenai. "We are taking control of the research process."

\section{DEMAND FOR DOCTORATES}

The emphasis on research is part of a broader set of changes at tribal colleges, most of which operate in self-governed nations. Unlike mainstream US universities, where undergraduates typically pursue four-year bachelor's degrees, tribal colleges have traditionally offered only two-year degrees and vocational training. Because many of them serve relatively poor communities with struggling primary and secondary schools, tribal colleges must provide remedial education to make up for gaps in students' basic skills and knowledge.

But several tribal colleges are also seeking 
to raise the level of their instruction by hiring teachers with more training. The percentage of staff with doctorates at tribal colleges rose by nearly $40 \%$ from 2003 to 2009 , going from about $8 \%$ to $11 \%$ of the total, according to figures from the American Indian Higher Education Consortium, based in Alexandria, Virginia.

The focus on science seems to be having an effect. Although enrolment at tribal colleges has been decreasing, the number of students pursuing degrees in science rose by more than $70 \%$ between 2003 and 2009, to about 1,200 students altogether. And eight tribal colleges now offer full four-year bachelor's degrees, with about 70 applied-science bachelor's programmes available.

The initiatives at tribal colleges are aided by a collection of programmes totalling about US $\$ 20$ million annually, from federal agencies such as the National Science Foundation (NSF).

"One of the reasons for the phenomenal growth in science enrolment at the tribal colleges is because they are able to provide undergraduate research opportunities," says Jody Chase, who manages the NSF's Tribal Colleges and Universities Program. Since 2001, that programme has provided $\$ 13.5$ million a year in funding to strengthen science courses at tribal colleges and other institutions serving Native Americans in Alaska and Hawaii.

Many of the research projects at tribal colleges focus on the local community. Researchers at Diné College in the Navajo Nation of Arizona, for example, worked with scientists from the US Geological Survey in Reston, Virginia, to investigate why residents in the Shiprock area of the reservation have roughly five times the rate of respiratory illness seen in nearby communities, despite a relatively low incidence of smoking. The area is home to some of the largest coalmining and electricity-generating operations in the United States.

By examining hospital records and monitoring indoor air quality in more than 130 homes, the researchers linked respiratory problems to high concentrations of particulate matter from the burning of coal in stoves not designed for that purpose ${ }^{2}$. The coal is provided at low or no cost to Navajo living near coal mines, as part of reservation lease agreements. The study has led to a large community-education campaign emphasizing, for example, the importance of leaving a window open. The college has also recommended that the tribe support a stove-replacement programme.

Scientists working outside the tribal colleges say that the focus on research is raising standards at these institutions. "They have had some really good successes," says David Burgess, a Native American cell biologist at Boston College in Massachusetts, who is involved with the Society for the Advancement of Chicanos and Native Americans in Science. Burgess says that the presentations given by many tribal-college students at the society's annual conference are getting stronger.

\section{GLOBAL PHENOMENON}

The research expansion has parallels in other countries such as Norway, New Zealand and Canada, where universities serving indigenous peoples are conducting studies on topics of local interest that would not otherwise be explored. "It is a global phenomenon," says Boni Robertson, a professor of indigenous policy at Australia's Griffith University in Queensland, and co-chair of the World Indigenous Nations Higher Education Consortium.

But along with their successes, America's

members don't have the necessary experience to undertake research - a problem that the American Indian College Fund (AICF), based in Denver, Colorado, is trying to rectify. It awards fellowships to faculty members at tribal colleges to start and finish $\mathrm{PhDs}$ and do their own research. Yet although the organization recruits intensively, each programme receives only a handful of applications.

Doing a $\mathrm{PhD}$ on a local Indian issue can be a tough slog, says Valerie (Pretty Paint) Small, a faculty member at Little Big Horn College on the Crow reservation in southern Montana. She has an AICF science fellowship to finish her $\mathrm{PhD}$ at Colorado State University in Fort Collins, where she is studying the invasion of a non-native tree species on Crow tribal lands. "So many people know so little about our contemporary issues," she says. "University professors don't make much of an effort to see where you might be coming from if you are on the reservation."

Faculty members at tribal colleges also struggle to publish their work, in part because of large teaching loads. To improve publication rates, colleges such as Salish Kootenai are forming writing groups for faculty members, and administrators are exploring ways to give staff time off for research. And the AICF hopes to start a peerreviewed, interdisciplinary journal this year that would publish research undertaken at tribal colleges.

Some scientists wonder whether tribal colleges would be better off expanding their partnerships with research-intensive universities rather than trying to do research on their own. "Why recreate those resources when they can

tribal colleges have run into some hurdles in their scientific efforts. Enrolment in science programmes has climbed, but the number of students completing two-year or four-year science degrees remained essentially flat from 2004 to 2009.

There are also concerns about the research at these institutions. Barbara Howard, a senior scientist at the non-profit MedStar Health Research Institute in Hyattsville, Maryland, has worked in Indian country since the late 1980s directing the Strong Heart Study, the largest epidemiological study of Native Americans. Howard welcomes the rise in undergraduate research at the tribal colleges, and says it is the best way to encourage students to go on to graduate school. But, she says, the tribal colleges need to improve in terms of their "research quantity and complexity".

A major obstacle is that many faculty partner with other institutions and develop new kinds of synergy?" asks Spero Manson, a Native American medical anthropologist who directs the Centers for American Indian and Alaska Native Health at the University of Colorado in Denver.

But Daniel Wildcat, acting dean of natural and social sciences at Haskell Indian Nations University in Kansas, says that doing research within tribal colleges allows Native Americans to "design their own research agendas", in which tribal values rather than those of outsiders determine what gets studied. @EEE EDITORIALP.5

Zoë Corbyn is a freelance journalist based in San Francisco.

1. Stevens, D. K., McDonald, K. \& Bishop, N. Environ. Bioindicators 4, 303-317 (2009).

2. Bunnell, J. E. et al. J. Environ. Public Health 2010 , 260525 (2010). 